\title{
A Review of the DCP-DN Pavement Design Method for Low Volume Sealed Roads: Development and Applications
}

\author{
Philip Paige-Green ${ }^{1}$, Gerhardt Daniel Van Zyl ${ }^{2}$ \\ ${ }^{1}$ Department of Civil Engineering, Tshwane University of Technology, Pretoria, South Africa \\ ${ }^{2}$ Mycube Asset Management Systems (Pty) Ltd., Cape Town, South Africa \\ Email: *Paigegreenconsult@gmail.com
}

How to cite this paper: Paige-Green, $P$. and Van Zyl, G.D. (2019) A Review of the DCP-DN Pavement Design Method for Low Volume Sealed Roads: Development and Applications. Journal of Transportation Technologies, 9, 397-422. https://doi.org/10.4236/jtts.2019.94025

Received: June 6, 2019

Accepted: September 9, 2019

Published: September 12, 2019

Copyright () 2019 by author(s) and Scientific Research Publishing Inc. This work is licensed under the Creative Commons Attribution International License (CC BY 4.0).

http://creativecommons.org/licenses/by/4.0/

\begin{abstract}
Widespread implementation of the DCP-DN design method for low volume roads has been promoted internationally over the past decade or so. The method has progressed from a simple determination of the in situ CBR investigation based on DCP-CBR correlations with respective cover requirements to a more sophisticated method using the DCP penetration data directly and omitting any need to use correlations with the CBR. This paper summarises the development of the method, and some of its advantages and compares the design structures with other recognised and widely implemented designs.
\end{abstract}

\section{Keywords}

Low Volume Roads, Design, Dynamic Cone Penetrometer, DCP, CBR

\section{Introduction}

The DCP DN pavement design method for low volume roads is based almost entirely on the results of field DCP surveys and laboratory DCP tests. The method was initiated in its simplest form more than 30 years ago and has been improved and updated. It is now being widely promoted as a simple yet appropriate low volume road design method in developing countries.

Most pavement design methods for low volume roads have been developed empirically by comparing the performance of existing roads with their properties and layer strengths in relation to the sub-grade support, the environmental and drainage conditions and the volume and types of traffic. This information usually results in a pavement catalogue or a structural number based on the combined contributions of each pavement layer to the overall bearing capacity of 
the pavement. The DCP-DN design method is no different and was originally developed after studying numerous (more than 1100) road sections in the then Transvaal Province in South Africa.

Following a more detailed investigation into the performance of 57 low volume roads throughout South Africa, the findings were compared with the earlier DCP design catalogues and confirmed their applicability and reliability. The general principle of the method is similar to the structural number concept. As its implementation in various countries has increased, more information regarding its development and scientific background has become necessary to support its validity and applicability.

This paper describes the early development of the method, reasons for implementing changes and the various changes and improvements made. The scientific basis for the method is discussed in detail and limitations on the use of the method identified.

\subsection{Apparatus and Early Investigations (Up to 1975)}

The Dynamic Cone Penetrometer (DCP) was developed in Australia [1] and introduced in South Africa in the late 1960s [2].

During the early 1970s, the Director of Roads of the then Transvaal Provincial Administration (TPA) commissioned an investigation in the Transvaal (now Gauteng, Limpopo, Mpumalanga and North West Provinces) to provide criteria for the pavement design of roads based on the performance of existing roads. John Burrow, a TPA engineer at the time, carried out the project during which 3000 kilometres of road (representing 20\% of the TPA bitumen road network) covering a range of road environments (traffic, climate, material types etc.), were investigated, with samples representing $25 \%$ of each road being collected. The sampling programme was random, with all sample sites being selected before each road was visited [3]. In all, about 14 volumes of data, analysis and interpretation were produced.

The condition of each road was carefully defined in terms of "failed" or "un-failed" (main criterion being the presence of a $20 \mathrm{~mm}$ rut but including other issues such as cracking and potholing). A test pit and DCP test were undertaken at each site, samples of each layer were taken for laboratory testing and traffic counts and deflection measurements collected as far as possible. In all more than 1100 test pits and DCP tests (not all tests could fully penetrate the pavements) were carried out.

The device used for this project consisted of a slightly different configuration to the current standard one shown in Figure 1 with a $30^{\circ}$ hardened steel cone, and a $10 \mathrm{~kg}$ hammer dropped through a distance of $460 \mathrm{~mm}$.

The roads were located in a variety of climatic zones (annual rainfall 300 to $>1600 \mathrm{~mm}$ ) and contained a range of base and subbase materials (ferricrete, weathered granite, dolerite, quartzite, diabase, calcrete, sandstones, etc.), in various forms (natural, water-bound macadam, crushed stone, penetration macadam, stabilised gravel, etc.). The roads varied in age from 6 to 45 years. The estimated 

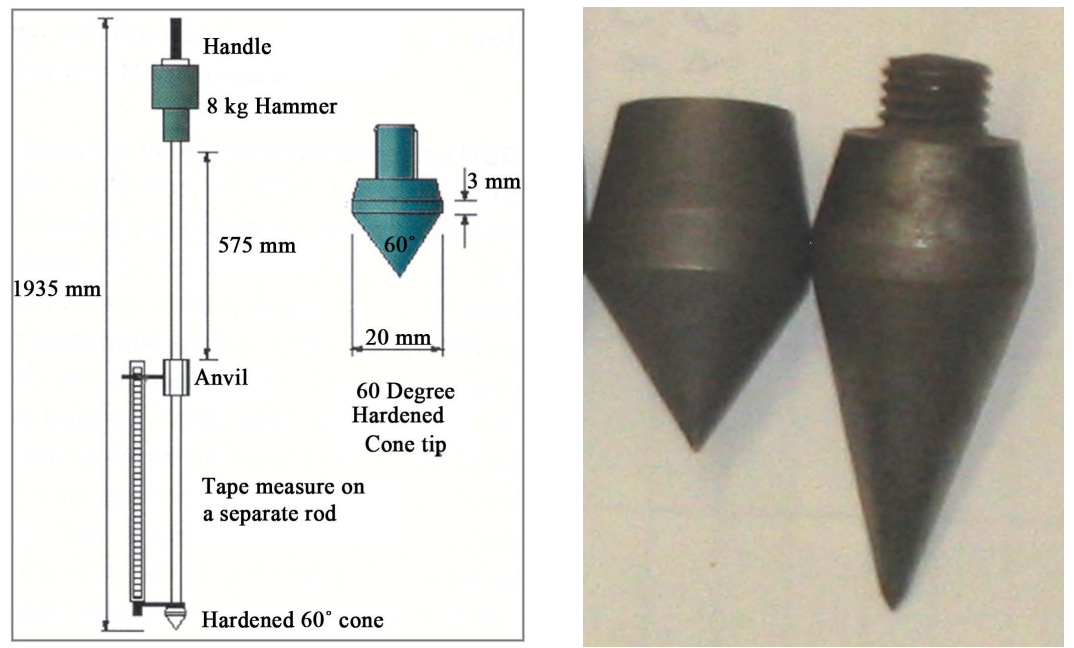

Figure 1. Standard DCP apparatus with current $60^{\circ}$ and previous $30^{\circ}$ cones.

cumulative traffic at the time on the roads investigated varied between $0.04 \times 10^{6}$ and $20 \times 10^{6}$ standard axles, with the majority of roads carrying relatively light traffic $(<500 \mathrm{vpd})$.

The Burrow investigation was mainly aimed at determining the required cover thickness of a pavement based on the subgrade properties and moisture content in relation to traffic loading. Additional work using the data obtained included the correlation of the DCP rate of penetration and CBR and analysis of the pavement structures and various other issues related to the DCP [4].

Several factors (including less equipment damage, ease of lifting the hammer and higher sensitivity to variation in strength within pavement layers) subsequently led to changes in the device. The characteristics of the current DCP are shown in Figure 1 with the main differences being the $60^{\circ}$ cone and an $8 \mathrm{~kg}$ hammer dropping $575 \mathrm{~mm}$. The two equipment configurations, however, provide the same energy.

Significant additional work has been carried out using the DCP over the years, primarily in South Africa, but also in Israel, Australia, the United Kingdom and the United States and more recently, in a number of African and Asian countries. It is now a recognised test with an ASTM standard [5].

\subsection{CBR-DCP Correlation}

Most engineers during the 1970s were familiar with the California Bearing Ratio (CBR) test for characterising the strength of pavement layers but had no feeling for the rate of DCP cone penetration in mm per blow-DCP Number (DN). Accordingly, the need existed to correlate these parameters. Kleyn [6] investigated the relationship between DCP ( $\mathrm{DN}$ in $\mathrm{mm} / \mathrm{blow}$ ) and CBR using the results of the laboratory and field investigations carried out by Burrow and produced a plot between the original $30^{\circ}$ cone DCP penetration rate and the CBR.

No correlation coefficient or regression equation was shown at the time and the regression model for this was only developed later [7] after correction for the 
change to a $60^{\circ}$ cone:

$$
\mathrm{CBR}=410 \times \mathrm{DN}^{-1.27}
$$

An exercise using electronic pixel identification of the original Kleyn [6] data was undertaken, and the coordinates of 703 identified points determined. The resultant regression model is as follows:

$$
\mathrm{CBR}=513.22 \times \mathrm{DN}^{-1.27}
$$

As a difference of approximately $20 \%$ from the original $30^{\circ}$ cone to the $60^{\circ}$ cone was reported [8], this adjustment was made. And the calculated model for the $60^{\circ}$ cone model gave an identical result.

$$
\mathrm{CBR}=410.58 \times \mathrm{DN}^{-1.27}
$$

The results of the above exercise are shown in Figure 2.

The CBR DN relationship (Equation (1)), as reported by Kleyn and Van Heerden [7], could thus be confidently accepted.

Many other correlation equations have subsequently been developed internationally [9]. Most of these correlations have similar models as follows:

$$
\log \mathrm{CBR}=A-B \times \log \mathrm{DCP}
$$

or

$$
\mathrm{CBR}=C / \mathrm{DCP}^{B}
$$

There are, however, some significant differences in the values of the $A, B$ and $C$ coefficients and the effects of these are illustrated in Table 1 [9] indicating wide differences in the predicted values. This is particularly noticeable for stronger materials (DN or DCP index $<15 \mathrm{~mm} / \mathrm{blow}$ ). It is also clear that the models are highly material dependent (Table 1 ), which is further illustrated by

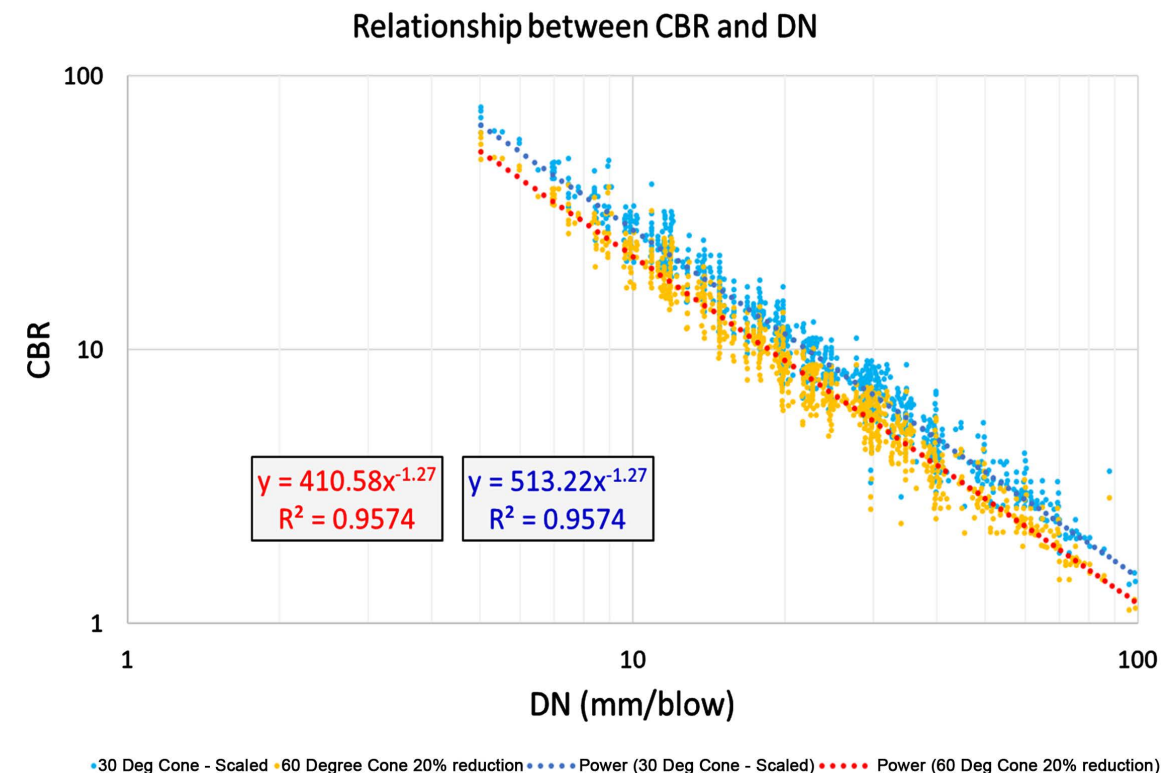

Figure 2. Results from scaled points and $20 \%$ reduction for change in cone angle (modified after [7]. 
Table 1. Models used in study by Livneh [9].

\begin{tabular}{cccccc}
\hline \multirow{2}{*}{ Curve \# } & \multirow{2}{*}{ Reference } & Material type & \multicolumn{3}{c}{ Coefficients } \\
\cline { 4 - 6 } & & & $\boldsymbol{A}$ & $\boldsymbol{B}$ & $\boldsymbol{C}$ \\
\hline 1 & Harison (1989) [10] & All - DN $>10$ & 2.560 & 1.160 & 363 \\
2 & Harison (1989) [10] & All - DN $<10$ & 2.540 & 1.120 & 347 \\
3 & Webster et al. (1992) [11] & All except CL and CH & 2.465 & 1.120 & 292 \\
4 & Ese et al. (1994) [12] & All & 2.438 & 1.065 & 274 \\
5 & Webster et al. (1994) [13] & CH only & 2.542 & 1.000 & 358 \\
6 & Webster et al. (1994)[13] & CL with CBR $<10 \%$ & 3.538 & 2.000 & 3452 \\
7 & Smith \& Pratt (1983) [14] & All & 2.620 & 1.270 & 417 \\
8 & Kleyn \& v Heerden (1983) [7] & All & 2.560 & 1.150 & 363 \\
9 & Seyman (2003) [15] & All & 2.256 & 0.954 & 180 \\
10 & Nazzal (2002) [16] & All & $*$ & & \\
11 & Phillips (2005) [17] & All & $*$ & & \\
12 & Livneh et al. (1999) [18] & All & 2.200 & 0.710 & $*$ \\
\hline
\end{tabular}

*Slightly different prediction models used.

Sampson [19] and Paige-Green et al. [20] (Table 2-the poor correlation in these models is notable). The effects of different cone angle and energy/mass ratios in the different countries during the early development of the DCP test must also be considered in the variations reported by Livneh [9].

Other differences in the prediction equations can probably be related to the different means of preparing the samples for the CBR test (handling oversize mostly) and variations in the test methods (compaction energies, mould volumes, interpretation of the penetration data, etc.). Some of the models also relate to DCP tests with the old $30^{\circ}$ cone that has subsequently been replaced with the standard $60^{\circ}$ cone, as well as different energy/mass ratios for the different DCP equipment. The poor reproducibility of the CBR test (see below) probably contributed to additional dispersion of the data in the correlation models and the variability of the test results given by Livneh [9].

The CBR test itself is known to produce notoriously variable results. Rallings ([21] studied the reproducibility and homogeneity (similar to repeatability) obtained during various proficiency test programmes carried out in Australia, concluding that "continuing reliance on the CBR hinders the development of pavement technology". It was also noted by Rallings [21] that "in all the programs investigated, less than $60 \%$ of results were within $\pm 30 \%$ of the median value. The largest relative spread (percentage) of reported proficiency test results was from 11 to 100 (median 50) and the smallest, 80 to 290 (median 140). The results of the two most recent studies discussed by Rallings are summarised in Table 3.

The high variability of the CBR test results is immediately obvious from these results, particularly the differences in Coefficient of Variation (CoV) and standard deviations of the "reproducibility" data between the two studies. Tests within the same laboratory are relatively "repeatable". 
Table 2. Regression models showing material dependence of CBR DCP correlation.

\begin{tabular}{ccc}
\hline Reference & Relationship & $\mathbf{r}^{2}(\mathbf{n})$ \\
\hline Sampson (1984) [19] & $\log _{e}(\mathrm{CBR})=5.82-0.95 \log _{\mathrm{e}}(\mathrm{DN})$ & $0.667(154)$ \\
Plastic materials only & $\log _{\mathrm{e}}(\mathrm{CBR})=5.98-1.13 \log _{\mathrm{e}}(\mathrm{DN})$ & $0.792(126)$ \\
PI $>$ 6 materials & $\log _{\mathrm{e}}(\mathrm{CBR})=6.17-1.25 \log _{\mathrm{e}}(\mathrm{DN})$ & $0.787(53)$ \\
PI $<6$ materials & $\log _{\mathrm{e}}(\mathrm{CBR})=5.73-0.84 \log _{\mathrm{e}}(\mathrm{DN})$ & $0.631(93)$ \\
PI $=0$ materials & $\log _{\mathrm{e}}(\mathrm{CBR})=5.87-0.69 \log _{\mathrm{e}}(\mathrm{DN})$ & $0.467(28)$ \\
$\begin{array}{c}\text { Paige-Green et al. }(2015)[20] \\
\text { Sands }(100 \%<2 \mathrm{~mm})\end{array}$ & $\log _{10}(\mathrm{CBR})=2.186-0.511 \log _{10}(\mathrm{DN})$ & $0.670(50)$ \\
\hline
\end{tabular}

Table 3. Repeatability and homogeneity results [21].

\begin{tabular}{ccccc}
\hline \multirow{2}{*}{$\begin{array}{c}\text { Sample } \\
\text { treatment }\end{array}$} & \multicolumn{2}{c}{ Report 710 } & \multicolumn{2}{c}{ Report 695 } \\
\cline { 2 - 5 } & Reproducibility & Homogeneity & Reproducibility & Homogeneity \\
\hline Mean CBR (\%) & 8.0 & 6.9 & 113 & 158 \\
CoV (\%) & 44 & 9 & 34 & 8 \\
Range & $2-24$ & & $40-200$ & 44 \\
\# of tests & 50 & 50 & 44 & 16.64 \\
$\sigma$ & 3.52 & 0.62 & 38.4 & \\
\hline
\end{tabular}

Similar conclusions were reached by Ingles [22] and Millard and O'Reilly [23] who indicated that the use of the soaked CBR test raises the question of variability. Overall the coefficient of variation of the test was shown to be of the order of $20 \%$-that is, with a true mean of $80 \%$, the CBR will range from $48 \%$ to $112 \%$. Smith and Pratt [14] carried out field tests to determine the repeatability of results from both the in situ California Bearing Ratio (CBR) test and the DCP and determined the correlations. Testing was carried out under field conditions, so results are those expected under such conditions rather than under ideal "laboratory-type" conditions. Results indicated that the coefficient of variation of CBR for the particular material at one test location could be of the order of $60 \%$ whilst that of the cone penetrometer could be of the order of $40 \%$.

Despite this, many pavement design methods allowed the characterisation of the subgrade and other materials from the DCP using correlations with the CBR with interchangeability of the models among different countries, irrespective of the local standard test methods (ASTM/AASHTO, BS, South African TMH, etc.).

Many specifications require a combination of the strength with various other soil "indicators". Paige-Green [24] showed that there is almost no correlation between the measured $\mathrm{CBR}$ and the traditional soil indicator properties such as grading modulus and plasticity. As shear strength (or stiffness) is generally the main criterion required in a pavement layer, potentially suitable materials may be rejected on the basis of another property not being complied with, despite the 
strength/stiffness being adequate. It has also been shown that there is very little correlation between the performance of low volume roads and the base CBR for a range of roads covering different climatic, traffic and material variations [25]. Other pavement characteristics, of course, may have contributed to deterioration of the pavement, but many low base strengths were determined in sound roads.

The DCP test provides a proxy for the in situ shear strength of the material [26], which is a function of the material properties (grading and plasticity) as well as parameters such as density and moisture. After the traditional initial borrow pit location and testing has proved potential materials to be suitable for the project, the DCP design method does not require that a wide range of material properties are continuously determined in the laboratory and all conventional specification requirements are met. This reduces the possibility that certain suitable materials (based on strength) may be rejected when not complying with properties that are only indirectly related to the material strength. As an example, using the percentage passing $0.075 \mathrm{~mm}$ limit [27], 45\% of the 165 base samples tested by Paige-Green [28] would have been rejected as unsuitable. Similarly, more than $40 \%$ of the samples had Plasticity Modulus values in excess of 325 , leading to rejection of their use on all but the strongest subgrades [27]. The minimum base requirement for CBR of $45 \%, 55 \%, 65 \%$ and $80 \%$ would reject $30 \%, 42 \%, 48 \%$ and $63 \%$ respectively of the materials that had performed satisfactorily in 57 roads investigated [28]. In the DCP DN design method, the DCP strengths (penetration rates) alone can be used for routine acceptance testing and quality control. This is in line with the growing approach for low volume road designs to work with local materials and not to reject marginal materials outright: rather assess each material on its own merits, including the use of base materials with 50\% CBRs e.g. [27] [29].

Use of the CBR test to characterise subgrade materials for pavement design usually entails taking a sample of the top 300 to $500 \mathrm{~mm}$ of subgrade material (depending on individual strata types and thicknesses within this zone). This is typically done once every $500-1000 \mathrm{~m}$ along the road and this data is used as a representative subgrade design CBR and to define uniform sections. This sampling method is poorly described in most design methods and varies from person to person: experience has shown that when thin layers $(<75 \mathrm{~mm}$ in the soil profile) of material with strengths widely divergent from each other are recorded, they can be treated differently. However, a composite sample of the materials is usually taken and an average subgrade CBR determined, which may not be representative of thinner weak layers in the subgrade. Despite the known variability of soils with depth (often over short distances), there is surprisingly little detail on how these samples should be collected in the literature, in relation to their depths, separation of different layers, interpretation of the results (i.e. weighting by depth, etc.). When the materials differ significantly in the top 500 $\mathrm{mm}$ (a common occurrence), the design CBR from a composite sample is essentially meaningless.

By using the DCP penetration rate from the field test, a fully representative 
profile of the subgrade strength at the prevailing moisture and density conditions for each layer (irrespective of thickness) to a depth of $800 \mathrm{~mm}$ can be obtained at a frequency of at least 5 - 10 times that of the CBR (DCP tests at least once every $100 \mathrm{~m}$ ). This allows a complete characterisation of the subgrade conditions (including thin layers with statistically different strength characteristics) and better identification of weak layers. A good statistical evaluation of uniform sections and representative subgrade design strengths at the in situ moisture and density conditions is thus obtained. Testing of laboratory samples with the DCP as described later has similar advantages.

It is important that material from borrow pits for possible use in structural layers should be located and investigated in the same manner and with the same tests as for conventional designs (i.e. including strength, compaction and indicator tests). However, it is recommended that laboratory testing as described later in this paper should be carried out using DCP penetration (DN) values instead of conventional CBR testing.

\subsection{Failure Criteria for Sealed Low Volume Roads}

There is an ongoing debate as when a sealed low volume road has failed and research and discussion in this area is urgently warranted. The conventional failure criteria of a $20 \mathrm{~mm}$ rut and cracking/deformation are not applicable to paved rural access roads, where passability is the main requirement. A paved road with ruts in excess of $40 \mathrm{~mm}$ deep, limited localised cracking and surface deformation up to $50 \mathrm{~mm}$ deep (or localised patching and repair) is generally considered to be a much more acceptable option by typical road users in these areas than a poor, usually un-maintained unsealed road that becomes impassable when wet. However, a paved road with numerous potholes is considered unacceptable in comparison with a potholed unsealed road.

In both the Burrow [3] and Paige-Green [25] investigations, a rut depth of 20 $\mathrm{mm}$ was considered as failed together with other issues such as cracking and potholing. However, certain roads with deeper ruts and no other distress were not considered as failed as they were providing significantly better levels of serviceability than the previous unpaved roads and other similar unpaved roads in the immediate vicinity.

\section{Principles of the DCP Design Method}

The DCP design method is based on four fundamental principles, namely:

- Minimum strength, defined as the minimum number of blows to penetrate $800 \mathrm{~mm}\left(\mathrm{DSN}_{800}\right)$.

- Balanced pavement structures.

- The expected (equilibrium) moisture content (EMC) under which the different pavement layers and subgrade will operate.

- A comparison of in situ strength with required strength and selecting a strengthening strategy. 


\subsection{Minimum Strength}

The data from the TPA Burrow investigation had shown that a pavement's structural design requirements, in million standard axles (MISA)) could be defined by the minimum DCP structural number $\left(\mathrm{DSN}_{800}\right)$ [4]. Figure 3 shows the correlation obtained between $\mathrm{DSN}_{800}$ and pavement bearing capacity (MISA), which was verified by HVS testing for prevailing moisture conditions [4] [6].

Note:

The term million standard axles (MISA) was initially used as the design traffic loading e.g. the pavement is designed to carry a certain number of $80 \mathrm{kN}$ axles (standard axles). When calculating the expected traffic loading over the design period, the number of heavy vehicles per day are converted to equivalent $80 \mathrm{kN}$ axles (E80s) per day by assigning the expected "E80s per heavy vehicle" for the type and loading of heavy vehicles on the road. The expected traffic loading is then expressed as million equivalent standard axles (MESA).

$$
\text { MISA }=C \times 10^{-9} \times \mathrm{DSN}_{800}^{3.5}
$$

This model is based on analysis of the original 1100 data points from the Burrows investigation [3] by Kleyn [4].

Using the above relationship for optimum moisture content conditions, guidelines for minimum structural capacities for different traffic classes were developed [4] [30]:

- Light traffic $(<0.2 \mathrm{MISA})$

$$
\mathrm{DSN}_{800} 80 \text { blows }
$$

- Medium traffic (0.2 - 0.8 MISA)

$$
\text { DSN }_{800} 150 \text { blows }
$$

- Heavy traffic (0.8 - 12.0 MISA)

$\mathrm{DSN}_{800} 300$ blows

Equation (6) was additionally verified by correlating the predicted change of rutting $(20 \mathrm{~mm})$ with several Heavy Vehicle Simulator (HVS) tests on pavements with known moisture contents (by introducing water) [31]. In addition, comparison between these models and the standard TPA pavement classification of 1978 (in terms of appropriate $\mathrm{DSN}_{800}$ for MISA) is shown in Figure 4. The

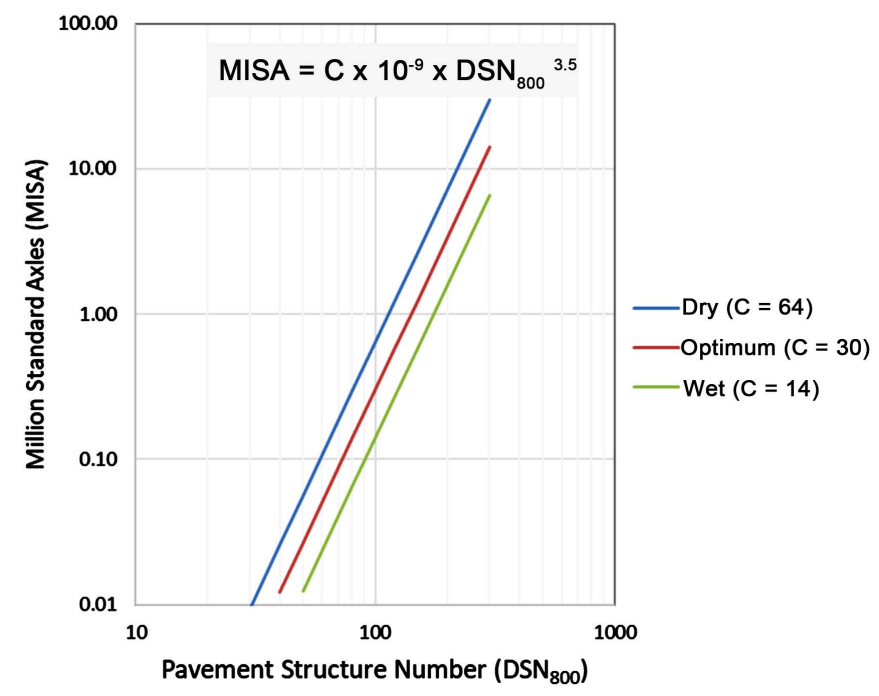

Figure 3. Relationship between $\mathrm{DSN}_{800}$ and MISA [4]. 


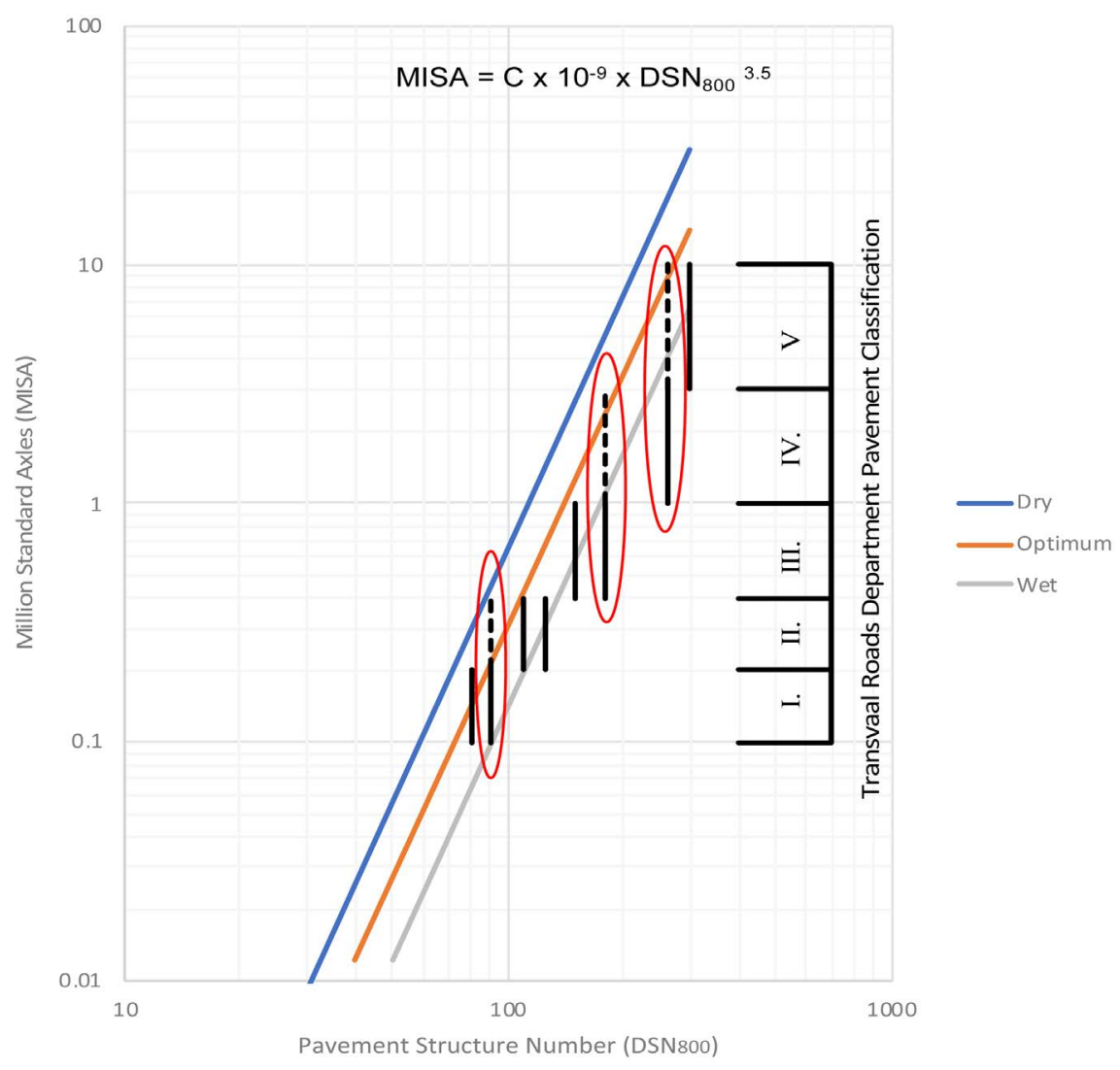

Figure 4. Comparison of Equation (6) model with standard TPA pavement classification and structures [4].

solid black lines in the red circled areas represent the $\mathrm{DSN}_{800}$ values for the then existing (1978 catalogue) pavement structures. The dotted lines within the red circled areas represent the load bearing capacity (MISA) of the particular $\mathrm{DSN}_{800}$, according to the HVS correlated DCP model. Based on this information, changes were made to the TPA pavement catalogue [31], effectively using pavement structures for one class higher than before.

\subsection{Pavement Strength Balance}

Based on the results from the Burrow investigation and Heavy Vehicle Simulator (HVS) testing, it was concluded that traffic moulding of a granular pavement would eventually result in a state of stress equilibrium throughout the structure, regardless of initial strength differences in constructed pavement layers.

The strength balance of a pavement structure is defined as the change in the strength of the pavement layers with depth. If the strength decrease is smooth and without any discontinuities, the pavement can be regarded as being in a state of balance.

The initial pavement balance, in terms of a Balance Number (BN) was defined as the percentage of the total $800 \mathrm{~mm}$ strength, in the top $12.5 \%(100 \mathrm{~mm})$. The $\mathrm{BN}_{100}$ of good granular pavements tested on the Transvaal Provincial road network were generally between 35 and 45 . The concept of deep and shallow pave- 
ments was then developed around these balance numbers i.e. $\mathrm{BN}_{100}$ lower than this range would be classified as "Deep" whereas $\mathrm{BN}$ higher than this range would be classified as "Shallow".

De Beer [32] furthered the balance concept through development of a classification system identifying the closest balance number of aCP test set and quantification of imbalances. The pavement depth was also expressed as the percentage of the total depth, with the balance curves developed shown in Figure 5.

Correlating distress development through HVS and DCP testing [33] quantified a relationship between the standard Load Equivalency Exponent " $n$ " used to determine equivalent standard axles $(F)$ and the BN (Equation (7)).

$$
n=0.044 \mathrm{BN}^{1.24}
$$

where

BN $=$ Balance Number.

Note:

As discussed later in the paper, a LEE ( $n$ ) of 4.2 is commonly used to calculate the design load in Million Equivalent Standard Axles (MESA). This equates to a $\mathrm{BN}$ of 39.5. If the selected $\mathrm{BN}<39.5$, this means that the design traffic may be over-estimated. The DCP-DN catalogue was developed with BN between 30 and 40 , resulting in a conservative approach.

\subsection{Equilibrium Moisture Content}

The DCP-DN is measured in the field at the in-situ moisture content (and density) of the pavement layers at the time of testing.

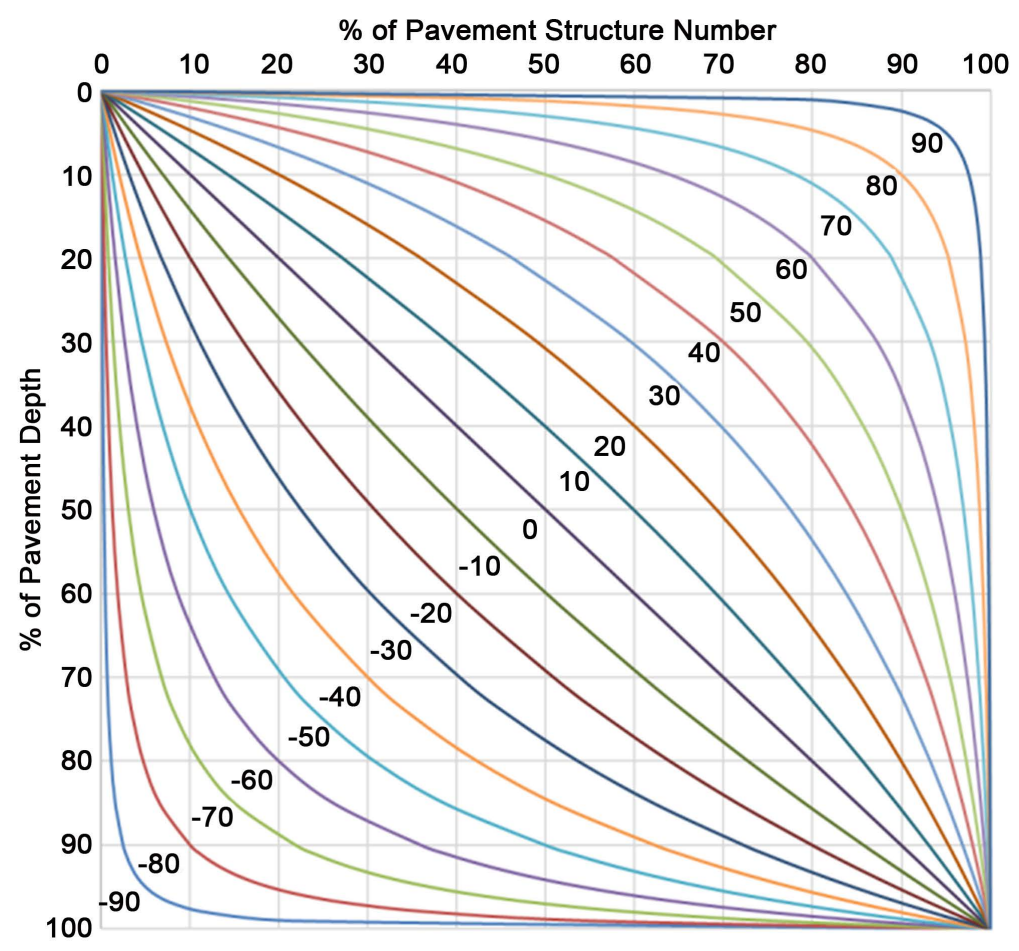

Figure 5. Standard pavement balance curves [32]. 
Depending on the type of pavement (surfaced/unsurfaced), climatic environment, season of testing, drainage systems and maintenance thereof, as well as the layer position within the pavement structure, the moisture content during the life of the pavement could differ from the time it was tested. Therefore, the strength of a particular layer, as tested, must be adjusted to the strength at the expected moisture content under which the layer will operate, referred to as the equilibrium moisture content (EMC).

Significant savings in the pavement cost can be achieved by using unsoaked strength designs in roads, and the DCP test is particularly useful for identifying the strength at a range of moisture contents.

Following the recommendations [33], the $80^{\text {th }}, 50^{\text {th }}$ or $20^{\text {th }}$ percentile of the range of $\mathrm{DN}$ values per layer is used as the representative $\mathrm{DN}$. The actual percentile depends on whether the anticipated long-term EMC in the pavement is respectively wetter than, the same as or drier than at the time of the DCP survey.

\subsection{Comparing in Situ Strength with Required Strength}

The example discussed previously requires pavement layer strengths as shown in Figure 6 (blue line). The representative DN per layer of a uniform design section, at the expected EMC, is plotted on the layer strength diagram and compared with the required layer strengths.

In this particular case, all layers except for the base layer, are strong enough to carry the design load. Possible options are to either:

- Strengthen or replace the base layer;

- Add an additional $150 \mathrm{~mm}$ layer of sufficient strength.

\section{DCP-CBR Method}

As discussed previously, most pavement design engineers during the 1970s to early 1990s were familiar with the California Bearing Ratio (CBR) test method to characterise the strength of materials but had no feeling for the DCP Number (DN) expressed in mm penetration per blow.

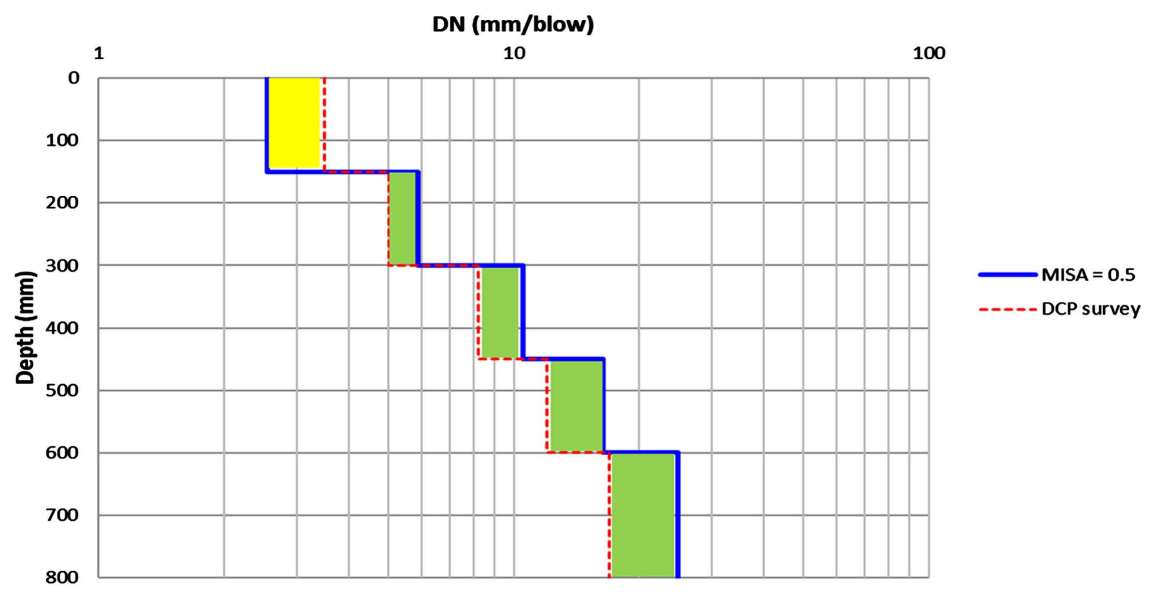

Figure 6. Measured versus required layer strengths. 
In addition to this, the soaked CBR of materials obtained from borrow pits, was a standard test result routinely produced by all materials laboratories. Therefore, the need existed to also convert the in-situ strength of materials (from DCP testing) to in-situ CBR (DCP CBR).

Kleyn and van Zyl [34] published a paper describing the use of the DCP for the design of light pavement structures and provided a catalogue of structures up to 100,000 standard axles (Table 4).

The catalogue was based on the DCP data from the Burrow investigation as analysed by Kleyn [4]. This was augmented by the results from the investigations of other more recently constructed roads, the pavement balance concept and Heavy Vehicle Testing results [6] [7] [8] [30] [32] [33] [35].

It is notable that the method was based on DCP penetration rates, which were subsequently converted back to CBR values based on the Kleyn model (Equation (1)).

This catalogue was subsequently used for the design of more than $800 \mathrm{~km}$ of low volume roads constructed by the TPA, which performed well in nearly every case.

The DCP design method was then incorporated into a manual on appropriate standards for low volume roads commissioned by the South African Department of Transport [36], which still converted the DCP penetration rates back to CBR using the Kleyn model.

During this time, the method was implemented on a number of projects, one being a sealed forestry road constructed in 1991 in South Africa, that had carried 400,000 axles after 4 years [37]. In 2018, this road was still in an excellent condition after carrying an estimated 800,000 to $1,000,000$ standard axles.

Table 4. Design catalogue for LVRs [34].

\begin{tabular}{cccc}
\hline Traffic class & $\boldsymbol{C}$ & $\boldsymbol{B}$ & $\boldsymbol{A}$ \\
\hline E80 $\times \mathbf{1 0 ^ { 6 }}$ & $\mathbf{0 . 0 0 3}-\mathbf{0 . 0 1 0}$ & $\mathbf{0 . 0 1 0 - 0 . 0 3 0}$ & $\mathbf{0 . 0 3 0 - \mathbf { 0 . 1 0 0 }}$ \\
\hline ADT & $\mathbf{5 0}-\mathbf{1 0 0}$ & $\mathbf{1 0 0}-\mathbf{2 0 0}$ & $\mathbf{2 0 0}-\mathbf{4 0 0}$ \\
\hline Base & $\mathrm{DN} \leq 8$ & $\mathrm{DN} \leq 5$ & $\mathrm{DN} \leq 4$ \\
$150 \mathrm{~mm}$ & $\mathrm{CBR} \geq 30$ & $\mathrm{CBR} \geq 50$ & $\mathrm{CBR} \geq 70$ \\
$\geq 98 \%$ Mod. AASHTO & $(\mathrm{G} 6)$ & $(\mathrm{G} 5)$ & $(\mathrm{G} 4)$ \\
Subbase & $\mathrm{DN} \leq 19$ & $\mathrm{DN} \leq 14$ & $\mathrm{DN} \leq 9$ \\
150 mm & $\mathrm{CBR} \geq 10$ & $\mathrm{CBR} \geq 15$ & $\mathrm{CBR} \geq 25$ \\
$\geq 95 \%$ Mod. AASHTO & $(\mathrm{G} 8)$ & $(\mathrm{G} 7)$ & $(\mathrm{G} 6)$ \\
Upper selected & $\mathrm{DN} \leq 33$ & $\mathrm{DN} \leq 25$ & $\mathrm{DN} \leq 19$ \\
150 mm & $\mathrm{CBR} \geq 5$ & $\mathrm{CBR} \geq 7$ & $\mathrm{CBR} \geq 10$ \\
$\geq 93 \%$ Mod. AASHTO & $(\mathrm{G} 10)$ & $(\mathrm{G} 9)$ & $(\mathrm{G} 8)$ \\
Lower selected & $\mathrm{DN} \leq 48$ & $\mathrm{DN} \leq 33$ & $\mathrm{DN} \leq 25$ \\
150 mm & $\mathrm{CBR} \geq 3$ & $\mathrm{CBR} \geq 5$ & $\mathrm{CBR} \geq 7$ \\
$\geq 90 \%$ Mod. AASHTO & $(\mathrm{G} 10)$ & $(\mathrm{G} 10)$ & $(\mathrm{G} 9)$
\end{tabular}

Note: The G classes are based on a combination of CBR strength and other material properties as described [38]. 
The design catalogue [36] was based on work done by Wolff et al. [39] which consisted of a relatively conservative catalogue based on the S-N method of analysis and used soaked CBR values and not the layer strength diagrams proposed by Kleyn and van Zyl [34]. The reason for the use of this catalogue at the time was that the existing DCP design catalogue [34] did not cover the high traffic envisaged for this road.

Paige-Green [25] [28] then investigated 57 low volume paved roads in South Africa including testing with a DCP on each road. Seventeen of these pavements were in the Transvaal and had been designed using the DCP method while the 30 in the other provinces were essentially upgraded gravel roads with minimal design (mostly shaping of the gravel wearing course and the application of a bituminous seal). This investigation was carried out primarily to assess the material properties in the pavement layers and not specifically for investigations of the structural design or capacity. However, simple back-analyses in terms of their DSN $_{800}$ and the traffic they had carried supported the catalogues proposed by Kleyn and van Zyl [34].

The Kleyn and van Zyl [34] DCP design method and catalogue was subsequently used on numerous roads in South Africa and played a major part in the International Labour Organisation(ILO) funded Gundo Lashu labour-based programme in Limpopo where many roads were upgraded from gravel to low volume paved standard, based on the DCP design method [40] [41].

\section{DCP-DN Method}

\subsection{Refinements}

Based on experience with the use of the DCP-CBR method, the DCP-DN method was subsequently refined with the following enhancements:

- Minor revision of the design catalogue;

- Moving away from converting DN to CBR due to poor correlations and material dependence;

- Moving away from the percentile moisture conversion to determine the representative $\mathrm{DN}$ value;

- Laboratory DCP evaluation of borrow pit materials as structural layers.

\subsection{Revision of the Design Catalogue}

\section{Improvement of strength balance and extension of traffic classes}

The pavement structures and DN values were adjusted slightly to improve pavement balance and the catalogue was extended to 6 traffic classes, up to 1 MISA, based on new information and existing requirements for roads in these categories [38]. The revised catalogue is shown in Table 5. The plots of the layer strength diagrams after adjustment are shown in Figure 7 and the strength with depth for the different traffic classes against various balance curves in Figure 8.

It is interesting to note that the pavement structures for higher traffic categories, in a wet environment, using the DCP-DN method, actually require better 


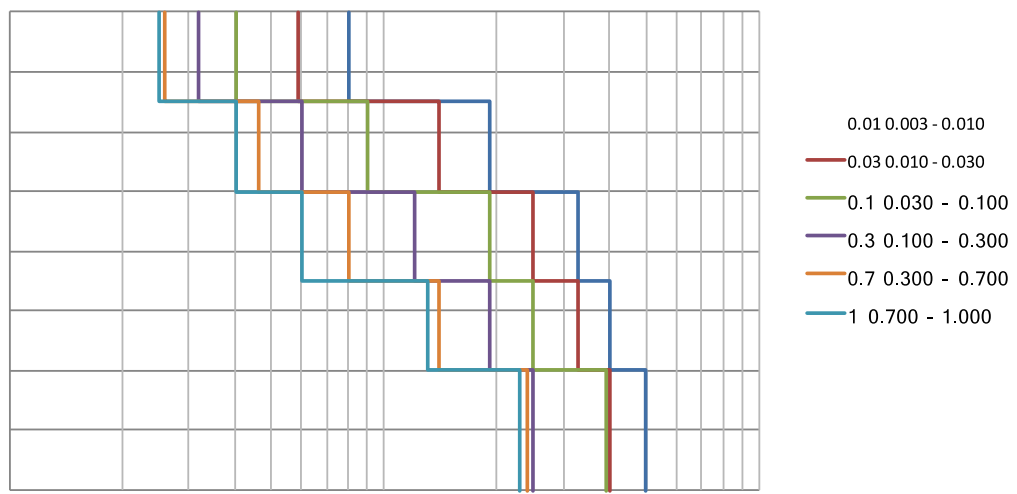

Figure 7. Layer strength diagram after adjustment and extension.

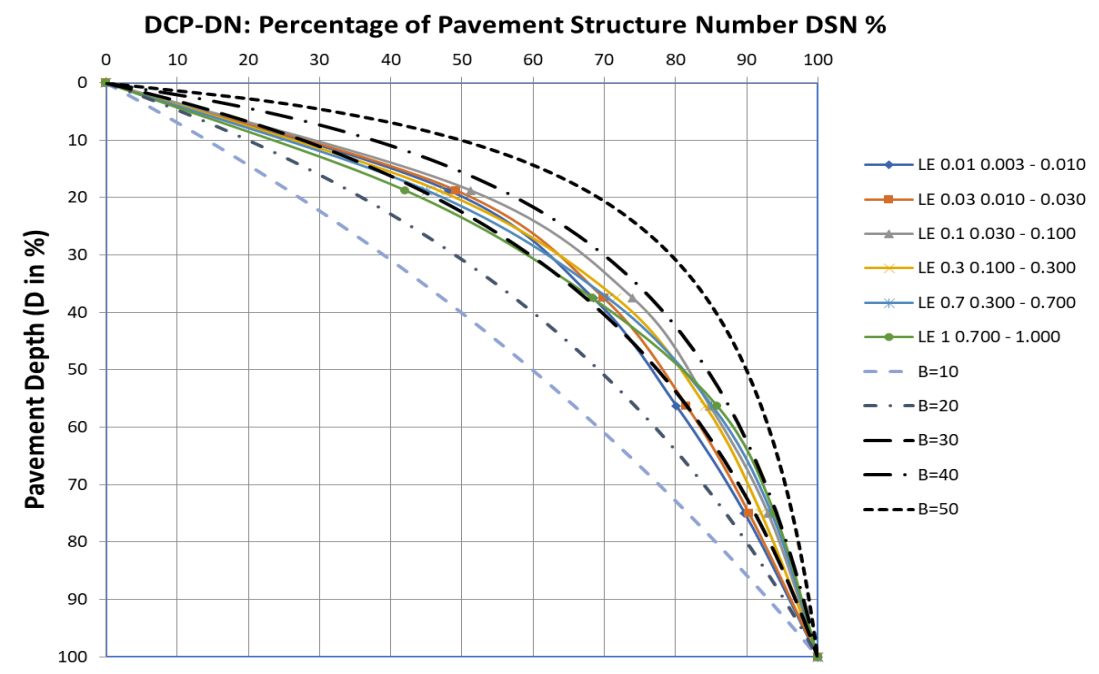

Figure 8. Plots of catalogue strengths with depth against standard balance curves.

Table 5. DCP-DN Design catalogue.

\begin{tabular}{|c|c|c|c|c|c|c|}
\hline Traffic Class & 0.01 & 0.03 & 0.1 & 0.3 & 0.7 & 1 \\
\hline MISA range & $0.003-0.01$ & $0.01-0.03$ & $0.03-0.10$ & $0.1-0.3$ & $0.3-0.7$ & $0.7-1.0$ \\
\hline $\begin{array}{c}0 \text { - } 150 \mathrm{~mm} \text { Base } \\
\geq 98 \% \text { Mod. AASHTO }\end{array}$ & $\mathrm{DN} \leq 8$ & $\mathrm{DN} \leq 5.9$ & $\mathrm{DN} \leq 4$ & $\mathrm{DN} \leq 3.2$ & $\mathrm{DN} \leq 2.6$ & $\mathrm{DN} \leq 2.5$ \\
\hline $\begin{array}{l}150-300 \mathrm{~mm} \text { Sub-base } \\
\geq 95 \% \text { Mod. AASHTO }\end{array}$ & $\mathrm{DN} \leq 19$ & $\mathrm{DN} \leq 14$ & $\mathrm{DN} \leq 9$ & $\mathrm{DN} \leq 6$ & $\mathrm{DN} \leq 4.6$ & $\mathrm{DN} \leq 4.0$ \\
\hline $\begin{array}{l}300 \text { - } 450 \text { mm Subgrade } \\
\geq 95 \% \text { Mod. AASHTO }\end{array}$ & $\mathrm{DN} \leq 33$ & $\mathrm{DN} \leq 25$ & $\mathrm{DN} \leq 19$ & $\mathrm{DN} \leq 12$ & $\mathrm{DN} \leq 8$ & $\mathrm{DN} \leq 6$ \\
\hline $\begin{array}{l}450-600 \mathrm{~mm} \\
\text { In situ material }\end{array}$ & $\mathrm{DN} \leq 40$ & $\mathrm{DN} \leq 33$ & $\mathrm{DN} \leq 25$ & $\mathrm{DN} \leq 19$ & $\mathrm{DN} \leq 14$ & $\mathrm{DN} \leq 13$ \\
\hline $\begin{array}{l}600-800 \mathrm{~mm} \\
\text { In situ material }\end{array}$ & $\mathrm{DN} \leq 50$ & $\mathrm{DN} \leq 40$ & $\mathrm{DN} \leq 39$ & $\mathrm{DN} \leq 25$ & $\mathrm{DN} \leq 24$ & $\mathrm{DN} \leq 23$ \\
\hline $\mathrm{DSN}_{800}$ & $\geq 39$ & $\geq 52$ & $\geq 73$ & $\geq 100$ & $\geq 128$ & $\geq 143$ \\
\hline
\end{tabular}


base materials and stronger structures than TRH 4 [38]. However, TRH4 provides the opportunity to design for the unsoaked condition, with its concomitant benefits, albeit potentially higher perceived risk (as discussed in Section 6), if the basic assumptions (drainage and maintenance) are not met. Observations of many higher standard roads have, however, shown that even material with a CBR of more than $80 \%$ will fail in shear if the local drainage conditions are unsatisfactory and the layer becomes soaked (due to high pore-water pressures under rapid vehicle loading).

\subsection{Re-Evaluation of $\mathrm{DSN}_{800}$}

As the Layer Strength Diagrams (LSD) are based primarily on the DCP structural number $\left(\mathrm{DSN}_{800}\right)$ at the prevailing in situ conditions, the plot of the $\mathrm{DSN}_{800}$ versus traffic was re-assessed for the increased catalogue range and is shown in Figure 9. The red points and trend line indicate the current DCP-DN catalogue (Layer Strength Diagram) criteria. There is a good correlation with the actual field data obtained [25] [28]. It should be noted that DCP testing was carried out at the time of the investigation and included all seasons, hence some of the very high $\mathrm{DSN}_{800}$ values obtained. In addition, the majority of the roads had not reached a failure condition at the time of the investigation, other than those approaching such a state and in contact with red dotted line in the figure. The results are thus conservative in relation to failure in most cases and purely show the plots of cumulative traffic versus pavement strength, indicating that the pavement structures will perform satisfactorily under at least the cumulative traffic counts plotted.

A theoretical comparison of the standard Layer Strength Diagrams with the mechanistic modelling of the stress distribution under various traffic loadings shown as tyre contact pressure (Figure 10) has also been carried out [42]. It is clear that the DCP Layer Strength Diagrams for the different categories remain stronger than the predicted shear strengths, except in the upper portions of the

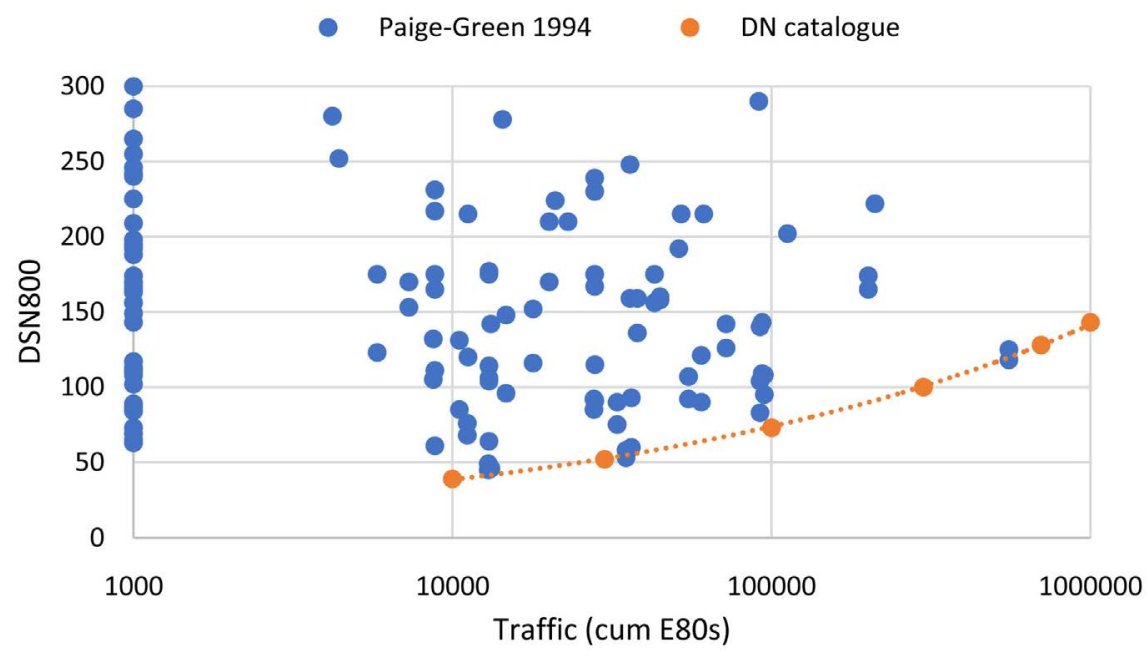

Figure 9. Plot of $\mathrm{DSN}_{800}$ versus traffic carried and best fit line for catalogue $\mathrm{DSN}_{800}$ values. 


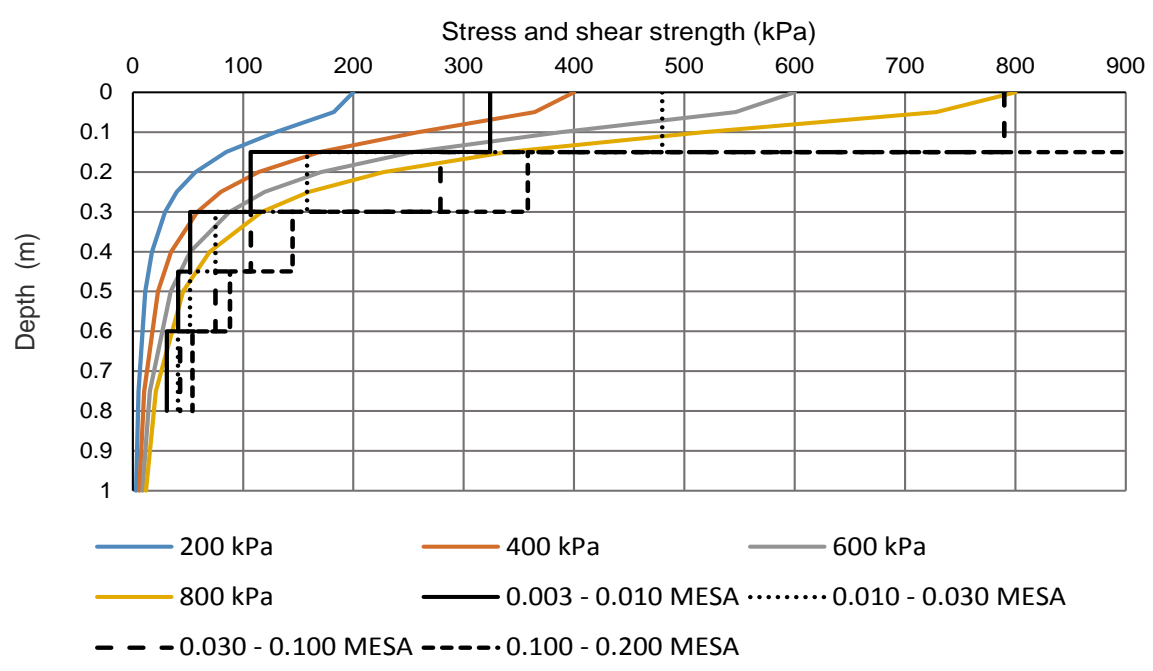

Figure 10. Comparison of stress distribution with layer strength diagrams [42].

pavements as the tyre contact pressures increase. Observations of such roads showed no surface failures due to overstressing, indicating that the upper in situ strengths were higher than tested, probably due to high densities, drier conditions, and visible strengthening of these areas by the prime penetration [42].

\subsection{Comparison of the DCP DN Design Catalogue with Other Design Catalogues}

A comparison of the DCP DN catalogue with some of the pavement structures provided in other conventional design guides has been carried out. For the Indian design catalogues for low volume roads [43] it was found that the $\mathrm{DSN}_{800}$ values were very similar. A similar exercise has been carried out comparing the SADC LVR catalogue of designs (DCP CBR approach) prepared by Gourley and Greening ([27], Road Note 31 [44] and TRH 4 [38]) and the results are summarised in Table 6 (full analyses are available in [45]).

It is clear that the structural capacities of the DCP-DN design catalogue are very similar to all of the other catalogues up to about 100,000 cumulative standard axles, after which they actually become more conservative. This is due to the allowance made for the use of unsoaked designs, which rely on good drainage and maintenance, compared with the soaked designs of most of the other catalogues. However most of these assume that the material is "considerably drier than 'soaked for most of the time, so the in situ strength should normally be substantially higher than the soaked values" [27].

\subsection{Moving Away from Converting DN to CBR Due to Poor Correlation}

Because of the variations in the CBR test, the mediocre correlations between CBR and DCP and the material dependence of the correlations, the use of the CBR was dropped entirely. Only the DN value, as measured directly in the field and laboratory was then used [46] [47]. It was considered that by using the DN 
Table 6. Comparison of $\mathrm{DSN}_{800}$ values for different design catalogues.

\begin{tabular}{|c|c|c|c|c|c|c|}
\hline \multirow{2}{*}{$\begin{array}{c}\text { Road } \\
\text { category/Design } \\
\text { catalogue }\end{array}$} & \multirow{2}{*}{$\begin{array}{l}\text { Subgrade } \\
\text { strength }\end{array}$} & \multicolumn{5}{|c|}{$\mathrm{DSN}_{800}$ by Pavement class ( $80 \mathrm{kN}$ axles) } \\
\hline & & $\begin{array}{l}3000 \text { to } \\
10,000\end{array}$ & $\begin{array}{c}10,000 \\
\text { to } 30,000\end{array}$ & $\begin{array}{c}30,000 \text { to } \\
100,000\end{array}$ & $\begin{array}{c}100,000 \text { to } \\
300,000\end{array}$ & $\begin{array}{c}300,000 \text { to } \\
1,000,000\end{array}$ \\
\hline DCP DN & * & 39 & 52 & 71 & 100 & 142 \\
\hline TRH 4 & * & 42 & 52 & $56-71$ & $63-73$ & $65-89$ \\
\hline \multirow{2}{*}{ ORN 31} & S2 & & & & 83 & 98 \\
\hline & S4 & & & & 81 & 95 \\
\hline \multirow{2}{*}{ DCP CBR } & S2 & & & $59(70)^{\star *}$ & $68(78)^{\star *}$ & $88(92)^{\star *}$ \\
\hline & S4 & & & $50(64)^{\star *}$ & $67(79)^{\star *}$ & $84(95)^{\star \star}$ \\
\hline \multirow[t]{2}{*}{ IRC } & \multirow[t]{2}{*}{$\mathrm{CBR}=3 \%$} & & & 83 & & \\
\hline & & & & 70 (no asphalt) & & \\
\hline
\end{tabular}

Subgrade is taken into account per layer in the individual pavement designs and a general design subgrade CBR is not used. ${ }^{* *}$ Forclimatic area according to Weinert $\mathrm{N}>4$ (and $\mathrm{N}<4$ ).

value directly, many of the in consistences caused by converting to CBR would be eliminated.

\subsection{Moving Away from the Percentile Moisture Conversion to Determine the Representative DN Value}

As discussed previously the $80^{\text {th }}, 50^{\text {th }}$ or $20^{\text {th }}$ percentile of the range of $\mathrm{DN}$ values per layer is used as the representative $\mathrm{DN}$, depending on whether the anticipated long-term EMC in the pavement is respectively wetter than, the same as or drier than at the time of the DCP survey.

Based on field evidence of comparing a unique DN value/point in both the wet and dry seasons and comparing these values with those indicated by the percentile conversion for a wide variety of materials, the need for a revised approach was considered necessary.

The principle of the DCP design method is to determine the strength at the expected in situ moisture conditions. If this is expected to be soaked, the strength is determined in the soaked condition (the same DCP penetration rate as required by the design catalogue must be achieved). If the pavement is expected to perform in a drier condition, the unsoaked strength (at OMC) is used for design purposes. Most other design methods use the soaked CBR for layer materials as a safety factor, knowing that the in situ strength will normally be higher than this as the in situ materials will in nearly all cases be unsoaked, particularly where the specified drainage conditions are installed.

Emery [48] studied the moisture contents in different layers in different climate areas in South Africa and published the Equilibrium to Optimum moisture content ratios for various pavement layers in different climatic areas of South Africa. It was shown that the base and subbase layers will normally operate at drier than $75 \%$ of OMC in moderate to dry areas and in wet areas at drier than OMC.

An improved approach would be to convert the DN at time of testing, at a 
specific moisture content, to the DN at the expected EMC.

Various attempts to relate this, through the CBR derived from the DCP, to the material G-classes used in South Africa have been made. The following correlations are used for materials in unsealed roads (Table 7) [49] and similar correlations for sealed roads [50].

The CBR values in Table 7 can be converted to DN values as shown in Table 8.

Through interpolation, the representative DN for each layer, at the measured moisture content is converted to the DN at the expected EMC. This EMC will in nearly all cases be in an unsoaked condition allowing the benefits of using significantly lower quality materials to achieve the operating DCP DN strength.

A slightly conservative approach is, however, applied in the DCP-DN design method, recommending that, unless soaked conditions are expected, both the

Table 7. Relationship between DCP CBR and G class for unsealed roads [49].

\begin{tabular}{cccccccc}
\hline & & \multicolumn{5}{c}{ Approximate field DCP-CBR: Sealed roads } \\
\cline { 3 - 8 } Material & Soaked & \multicolumn{2}{c}{ Subgrade } & \multicolumn{4}{c}{ Wearing course } \\
\cline { 3 - 8 } classification & CBR & Wet & $\begin{array}{c}\text { Dry } \\
\text { climate }\end{array}$ & Very dry & $\begin{array}{c}\text { Dry } \\
\text { state }\end{array}$ & $\begin{array}{c}\text { Moderate } \\
\text { state }\end{array}$ & $\begin{array}{c}\text { Damp } \\
\text { state }\end{array}$ \\
\hline s4 & 80 & 109 & 111 & 318 & 228 & 164 & 117 \\
G5 & 45 & 80 & 85 & 244 & 175 & 126 & 90 \\
G6 & 25 & 59 & 65 & 186 & 134 & 96 & 69 \\
G7 & 15 & 45 & 50 & 147 & 106 & 76 & 54 \\
G8 & 10 & 38 & 43 & 122 & 88 & 63 & 45 \\
G9 & 7 & 33 & 37 & 103 & 75 & 54 & 38 \\
G10 & 3 & 20 & 24 & 70 & 51 & 36 & 26 \\
\hline
\end{tabular}

Note: moisture contents are expressed as ratios of in situ to Mod AASHTO optimum moisture content as follows: very dry $=0.25$; dry $=0.5$; moderate $=0.75$; damp $=1.0$.

Table 8. Relationship between DCP DN and G-class for different moisture conditions.

\begin{tabular}{|c|c|c|c|c|c|c|c|}
\hline \multicolumn{8}{|c|}{ Relationship between DN and G class for sealed roads } \\
\hline \multirow{3}{*}{$\begin{array}{c}\text { Material } \\
\text { classification }\end{array}$} & \multirow{3}{*}{$\begin{array}{l}\text { Soaked } \\
\text { CBR/DN }\end{array}$} & \multicolumn{6}{|c|}{ Approximate field $\mathrm{DN}$ - sealed road } \\
\hline & & \multicolumn{2}{|c|}{ Subgrade } & \multicolumn{4}{|c|}{ Base, subbase and selected layers } \\
\hline & & Wet & Dry & $\begin{array}{c}\text { Very dry } \\
25 \% \text { OMC }\end{array}$ & $\begin{array}{c}\text { Dry } \\
50 \% \text { OMC }\end{array}$ & $\begin{array}{c}\text { Moderate } \\
75 \% \text { OMC }\end{array}$ & $\begin{array}{l}\text { Damp } \\
\text { OMC }\end{array}$ \\
\hline G4 & 3.62 & 2.90 & 2.80 & 1.22 & 1.59 & 2.06 & 2.68 \\
\hline G5 & 5.70 & 3.62 & 3.45 & 1.50 & 1.95 & 2.53 & 3.30 \\
\hline G6 & 9.05 & 4.60 & 4.26 & 1.86 & 2.41 & 3.14 & 4.07 \\
\hline G7 & 13.53 & 5.70 & 5.24 & 2.24 & 2.90 & 3.77 & 4.93 \\
\hline G8 & 18.62 & 6.51 & 5.90 & 2.60 & 3.36 & 4.37 & 5.70 \\
\hline G9 & 24.65 & 7.27 & 6.65 & 2.97 & 3.81 & 4.93 & 6.51 \\
\hline G10 & 48.04 & 10.79 & 9.34 & 4.02 & 5.16 & 6.79 & 8.77 \\
\hline
\end{tabular}


base and subbase be designed at OMC strengths. However, if sufficient evidence exists that the pavement will be properly drained and maintained and remain significantly dry of OMC, materials yielding the required DN value at $75 \%$ of OMC could be considered for these layers in moderate to dry areas.

\subsection{Evaluation of Borrow Pit Materials as Structural Layers}

Comparing the in situ strength and the required strength of a pavement to carry the design load very often indicates the need to import additional layers e.g. subbase and/or base of appropriate quality. Historically, using the DCP CBR design approach, the required strengths of these additional layers were expressed in terms of CBR and suitable materials sourced.

The drive towards optimising the use of local materials resulted in testing the DN of available materials at different moisture contents and compaction efforts in the laboratory. Using the DN value determined at different moisture contents and densities for selecting materials as the sole determinant of layer strength would also permit the use of a wide range of locally occurring materials that would otherwise have been rejected. The influence of grading and plasticity of such materials is indirectly measured by the resistance to penetration and would thus not have to be specified separately as discussed earlier. However, for any project a conventional material location and borrow pit identification process would be initially be carried out as described previously in the paper. The conventional limits for grading and plasticity would be considered in this decision although the primary selection criterion would be the strength (as DN in $\mathrm{mm} / \mathrm{blow}$ ) as measured in the laboratory by the DCP. Materials with a grading modulus of less than 1 are normally considered to be unacceptable for structural layers in roads during routine testing and control.

The DN resultsof a material tested in the laboratory as illustrated in Figure 11 , according to the DN design catalogue (Table 5), show that it could be used, at $98 \%$ BS heavy density (equivalent to $98 \%$ AASHTO T108 density), as a base material for a design load of 0.1 MISA $(\mathrm{DN}<4)$.

DN at varying $\mathrm{MC}$ and \% compaction

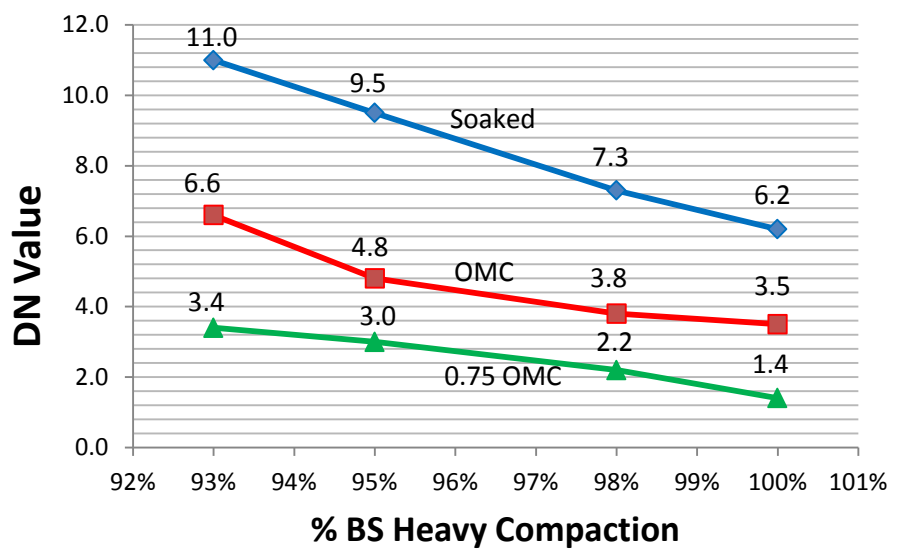

Figure 11. DN at moisture contents and compaction efforts. 
The information in Figure 11 should be carefully studied in conjunction with the shape of the compaction curves used to determine the Maximum Dry Density (MDD) and Optimum Moisture Content (OMC) as these are indicative of the compactability and moisture sensitivity of the materials, both dependent on the grading and plasticity [25]. The shapes and locations of the "curves" relative to each other in Figure 11 are also indicative of the compactability and moisture sensitivity of the materials and can be used as a proxy for additional plasticity and particle size testing.

\subsection{Move towards an Environmentally Optimised Design (EOD) Approach}

A further development with the DCP-DN method was combining it with the Environmentally Optimised Design (EOD) concept [51] for low volume roads. This entails the definition of uniform sections along the road based on the DCP DN value, including local environmental issues (e.g. topography, drainage, etc.) that will affect the pavement design and performance. In this way, the pavement design (particularly in terms of the expected moisture conditions) can be varied to accommodate localised drainage conditions. Although it has been clearly shown that the moisture content in roads seldom exceeds the optimum moisture content for the materials involved [48] [52] [53], localised impeded drainage conditions may require the use of soaked material results over limited sections of the roads.

\subsection{Development of Software for Design of Low Volume Roads}

To facilitate implementation of the DCP DN method, AfCAP supported the development of a software package that analyses the field data and assists with determining the design for low volume roads. The software is freely available and can be downloaded from the AfCAP web site (http://www.research4cap.org/SitePages/LVRDCPSoftware.aspx).

\subsection{Limitations on Use of DCP DN Method}

The DCP DN method is based on testing of a wide variety of materials (igneous, sedimentary and metamorphic rocks as well as pedogenic and transported soils) under a range of traffic and loading conditions and in a variety of climatic and drainage environments. It should thus be applicable to most design situations, bearing in mind that it caters for saturated conditions if necessary, in environments subjected to high rainfalls or periodic flooding.

The method, however, cannot be used directly if the proposed road is in deep cut or on a high fill, where the final formation level (selected subgrade or capping layer) is either below or above the currently exposed soil surface. In such cases, the cutting or embankment must be constructed to the formation height before testing of the support, using the DCP for the pavement design. However, in the case of embankments, the imported material to be used for the embank- 
ment can be tested using the DCP in the laboratory to understand its properties: this material will provide the final construction level on which the pavement can then be designed using the DCP.

Similarly, in soil cut areas, the final "subgrade" level can be tested using the DCP after excavation. However, if the cut is in rock, testing with the DCP would not give any meaningful results.

Although testing of very stony materials will often give a DCP result, this can be considered unreliable due to the number of additional blows that may be necessary to break or "by-pass" larger materials.

\section{Conclusions}

The original DCP design method was proposed in 1987 based on an extensive investigation of more than 1100 sites on a wide variety of roads in the then Transvaal Province of South Africa. It has evolved considerably since then. Based on numerous field studies and investigations it currently omits all reference to the CBR test (no DCP-CBR correlations are introduced in the method) and is known as the DCP-DN design method. It is clear that the DCP-DN design method compares favourably, if not slightly conservatively, against various other methods of design, especially for very low volume roads.

The design method is based directly on the results obtained in the field on the in-situ materials down to a depth of $800 \mathrm{~mm}$. It also allows an improved statistical assessment of the actual in situ subgrade strength (both in depth and longitudinal extent) compared with conventional CBR design methods, identifying all strength variations to a depth of $800 \mathrm{~mm}$ and allowing a more refined differentiation of uniform subgrade sections.

Comparison of the structural numbers of various road design methods converted to DCP $\mathrm{DSN}_{800}$ values shows remarkably close agreement with the DCP structural numbers used in the DCP DN design catalogue at low design traffic (up to $0.1 \mathrm{MISA}$ ). The DCP-DN design catalogues then become gradually more conservative with increased traffic load classes. This is a function of reducing the risk of moisture-related failure at higher traffic volumes.

\section{Acknowledgements}

This paper was produced as part of an AfCAP review project [45] and the contribution of AfCAP is gratefully acknowledged.

Invaluable contributions to this document have also been made by Messrs Jon Hongve, Mike Pinard, Eduard Kleyn, Mr Les Sampson and Dr Morris de Beer. Mr Nkululeko Leta, the AfCAP Programme Manager, is also thanked for his support.

\section{Conflicts of Interest}

The authors declare no conflicts of interest regarding the publication of this paper. 


\section{References}

[1] Scala, A.J. (1956) Simple Methods of Flexible Pavement Design Using Cone Penetrometers.

[2] Van Vuuren, D.J. (1969) Rapid Determination of CBR with the Portable Dynamic Cone Penetrometer. The Rhodesian Engineer, Paper No. 105.

[3] Burrow, J.C. (1975) Investigation of Existing Pavements in the Transvaal. Transvaal Roads Department, Pretoria, Report L1/75.

[4] Kleyn, E.G. (1984) Aspects of Pavement Evaluation and Design as Determined with the Aid of the Dynamic Cone Penetrometer. M Eng Thesis, University of Pretoria, Pretoria. (In Afrikaans)

[5] American Society for Testing Materials (ASTM) (2018) Standard Test Method for Use of the Dynamic Cone Penetrometer in Shallow Pavement Applications: ASTM D6951/D6951M-18. ASTM International, West Conshohocken.

[6] Kleyn, E.G. (1975) The Use of the Dynamic Cone Penetrometer (DCP). Transvaal Roads Department, Pretoria, Report L2/75. (In Afrikaans)

[7] Kleyn, E.G. and Van Heerden, M.J.J. (1983) Using DCP Soundings to Optimise Pavement Rehabilitation. Proceedings of Annual Transportation Convention, Johannesburg, 25-29 July 1983, Volume 3, 319-334.

[8] Kleyn, E.G. and Savage, P.F. (1982) The Application of the Pavement DCP to Determine the Bearing Properties and Performance of Road Pavements. International Symposium on Bearing Capacity of Roads and Airfields, Trondheim, 23-25 June 1982.

[9] Livneh, M. (2007) Uncertainty Associated with Pre-Defined Correlative Expressions of Various In-Situ Test Outputs. FAA Worldwide Airport Technology Transfer Conference, Atlantic City.

[10] Harison, J.A. (1989) Correlation between California Bearing Ratio and Dynamic Cone Penetrometer Strength Measurements of Soils. Australian Road Research, 19, 130-136.

[11] Webster, S.L., Grau, R.H. and Williams, R.P. (1992) Description and Application of Dual Mass Dynamic Cone Penetrometer. Instruction Report No. GL-92-3, U.S. Army Engineer Waterways Experiment Station, Vicksburg.

[12] Ese, D., Myre, J., Noss, P. and Vaerness, E. (1994) The Use of the Dynamic Cone Penetrometer (DCP) for Road Strengthening Designs in Norway. In: Proceedings of the 4th International Conference on the Bearing Capacity of Roads and Airfields, University of Minnesota, Minneapolis.

[13] Smith, R.B. and Pratt, D.N. (1983) A Field Study of In-Situ California Bearing Ratio and Dynamic Cone Penetrometer Testing for Subgrade Investigation. Australian Road Research, 13, 285-293.

[14] Webster, S.L., Brown, R.W. and Porter, J.R. (1994) Force Projection Site Evaluation Using the Electric Cone Penetrometer (ECP) and the Dynamic Cone Penetrometer (DCP). Technical Report No. GL-94-17, Air Force Civil Engineering Support Agency, US Air Force, Tyndall Air Force Base, FL.

[15] Seyman, E. (2003) Laboratory Evaluation In-Situ Tests as Potential Quality Control/Quality Assurance Tools. M.Sc. Thesis, Louisiana State University and Agricultural and Mechanical College, Baton Rouge.

[16] Nazzal, M. (2002) Field Evaluation of In-Situ Test Technology for QC/QA during Construction of Pavement Layers and Embankments. M.Sc. Thesis, Louisiana State University and Agricultural and Mechanical College, Baton Rouge. 
[17] Phillips, L.D. (2005) Field Evaluation of Rapid Airfield Assessment Technologies. M.Sc. Thesis, Mississippi State University, Starkville.

[18] Livneh, M., Livneh, A.N. and Ishai, I. (1999) Israeli Experience with the Regular and Extended Dynamic Cone Penetrometer for Pavement and Subsoil-Strength Evaluation. In: Tayabji, S.D. and Lukanen, E.O., Eds., Non-Destructive Testing of Pavements and Back-Calculation of Moduli, Vol. 3, ASTM STP 1375, ASTM, West Conshohocken.

[19] Rallings, R. (2014) CBR Test-A Case for Change? Australian Geomechanics, 49, 41-55.

[20] Sampson, L.R. (1984) Investigation of the Correlation between CBR and DCP. Technical Note TS/33/84. National Institute for Transport and Road Research, CSIR, Pretoria.

[21] Paige-Green, P., Pinard, M.I. and Netterberg, F. (2015) Low-Volume Roads with Neat Sand Bases. Transportation Research Record: Journal of the Transportation Research Board, 2474, 56-62.

[22] Ingles, O. (1974) Compaction in Soil Mechanics: New Horizons. Butterworths, London.

[23] Millard, R.S. and O'Reilly, M.P. (1964) Standards of Road Building Practice in the Tropics. Proc 2nd Australian Road Research Board Conference, Vol. 2 (Part 2), 830-854.

[24] Paige-Green, P. (2015) Are We Doing Unnecessary or Incorrect Material Testing for Low Volume Roads? Proceedings of 2 nd International Conference on Transportation in Africa, Palapye, 25-27 November 2015, 11 p.

[25] Paige-Green, P. (1999) Materials for and Construction of Sealed Low Volume Roads. Journal of the Transportation Research Board, 1652, 163-171. https://doi.org/10.3141/1652-21

[26] Ayers, M.E., Thompson, M.R. and Uzarski, D.R. (1989) Rapid Shear Strength Evaluation of in Situ Granular Materials. Journal of the Transportation Research Board, 1227, 134-146.

[27] Gourley, C.S. and Greening, P.A.K. (1999) Performance of Low Volume Sealed Roads: Results and Recommendations from Studies in Southern Africa. TRL Project Report PR/OSC/167/99, Crowthorne.

[28] Paige-Green, P. (1994) Recommendations on the Use of Marginal Base Course Materials in Low Volume Roads in South Africa. Department of Transport, Pretoria, Research Report RR 91/201.

[29] Cook, J.R., Petts, R.C. and Rolt, J. (2013) Low Volume Rural Road Surfacing and Pavements: A Guide to Good Practice.

[30] De Beer, M. (1991) Use of the Dynamic Cone Penetrometer (DCP) in the Design of Road Structures. Proceedings of the 10th Regional Conference for Africa on Soil Mechanics and Foundation Engineering, Maseru, 23-27 September 1991, 167-176.

[31] Marais, G.P., Maree, J.H. and Kleyn, E.G. (1982) The Impact of HVS Testing on Transvaal Pavement Design. Proceedings of Annual Transportation Convention, Pretoria, July 1982.

[32] De Beer, M., Kleyn, E.G. and Savage, P.F. (1988) Towards a Classification System for the Strength-Balance of Thin Flexible Pavements. Proceedings of Annual Transportation Convention, Pretoria, Vol. 4D.

[33] Kleyn, E.G., Freeme, C. and Terblanche, L. (1985) The Impact of Heavy Vehicle Simulator Testing in Transvaal. Proceedings of Annual Transportation Convention: 
Accelerated Testing of Pavements, Pretoria, July 1985, S350.

[34] Kleyn, E.G. and Van Zyl, G.D. (1987) Application of the Dynamic Cone Penetrometer (DCP) to Light Pavement Design. Transvaal Provincial Administration, Pretoria, Laboratory Report L4/87.

[35] Kleyn, E.G., De Wet, L.F. and Savage, P.F. (1989) The Development of an Equation for the Strength Balance of Road Pavement Structures. The Civil Engineer in South Africa, 31, 45-50.

[36] Department of Transport (DOT) (1993) Towards Appropriate Standards for Rural Roads: Discussion Document. Department of Transport, Pretoria, Research Report RR 92/466/1.

[37] Jones, D.J. and Paige-Green, P. (1995) The Use of Performance Data from an Upgrading Experiment to Assist with the Appropriate Design of Roads for New Communities. Proceedings of 11 th Regional Conference for Africa on Soil Mechanics and Foundation Engineering, Cairo, December 1995.

[38] Committee of Land Transport Officials (COLTO) (1996) Structural Design of Flexible Pavements for Interurban and Rural Roads. COLTO, Pretoria, Draft TRH4.

[39] Wolff, H., van Zyl, G.D., Emery, S.J. and Paige-Green, P. (1995) A Design Catalogue for Low Volume Roads Developed for South African Conditions. Proceedings of 6 th International Conference on Low Volume Roads, Minneapolis, 118-129.

[40] Paige-Green, P. and Hongve, J. (2003) Alternatives to Conventional Gravel Wearing Courses on Low Volume Roads. 10th Regional Seminar for Labour-Based Practitioners, Arusha, October 2003.

[41] Paige-Green, P., Hongve, J., Sampson, L.R. and Cassiem, I. (2004) Labour-Based Bitumen Roads as Cost-Effective Alternatives to Conventional Gravel Wearing Courses. 8th CAPSA, Sun City, September 2004.

[42] Paige-Green, P. (2015) An Alternative Philosophy on the Deterioration and Design of Low Volume Roads. Proceedings of CAPSA 2015, Sun City, August 2015, 386-391.

[43] Indian Roads Congress (IRC) (2015) Guidelines for the Design of Flexible Pavements for Low Volume Rural Roads. IRC-SP-72-2015, New Delhi.

[44] Transport Research Laboratory (TRL) (1993) A Guide to the Structural Design of Bitumen-Surfaced Roads in Tropical and Sub-Tropical Countries. Overseas Road Note 31 (4th Edition), Overseas Development Administration, London.

[45] African Community Access Partnership (AfCAP) (2018) Research Background to the DCP-DN Pavement Design Method for Low Volume Sealed Roads: Final Report. AFCAP Project Reference: RAF2128B. ReCAP, Thame.

[46] Pinard, M.I., Paige-Green, P. and Hongve, J. (2015) Developments in Low Volume Roads Technology: Challenging Conventional Paradigms. CAPSA, Sun City, August 2015.

[47] Pinard, M.I., Paige-Green, P. and Hongve, J. (2015) A New Approach to the Upgrading of Gravel Roads to Low Volume Sealed Roads Based on Dynamic Cone Penetrometer Testing.

[48] Emery, S.J. (1985) Prediction of Moisture Content for Use in Pavement Design. PhD Thesis, University of the Witwatersrand, Johannesburg.

[49] Shackleton, M.C. and Emery, S.J. (1985) Investigation of CBR versus Moisture Content Relationships for Untreated Materials. Report TS/4/85. NITRR, CSIR, Pretoria.

[50] Paige-Green, P., Lea, J. and Barnado, C. (1999) Relationship between in Situ DCP Strength and Soaked CBR. Technical Report TR-99/003. Division of Roads and 
Transport Technology, CSIR, Pretoria.

[51] Transport Research Laboratory (TRL) (2008) Low Volume Rural Road Standards and Specifications: Part III Application of LVRR Standards and Specifications. Mainstreaming Appropriate local Road Standards and Specifications and Developing a Strategy for the MPWT Research Capacity. SEACAP 3. TRL, Crowthorne.

[52] Croney, D. (1977) The Design and Performance of Road Pavements. HMSO, London.

[53] Haupt, F.J. (1980) Moisture Conditions Associated with Pavements in Southern Africa. M.Sc. Dissertation, University of the Witwatersrand, Johannesburg. 